\title{
Acute liver failure and transplantation in children
}

\author{
S Horslen, MB ChB, MRPC, FRCPCH \\ Hepatobiliary Program, Seattle Children's, Department of Pediatrics, School of Medicine, University of Washington, Seattle, USA
}

Corresponding author: S Horslen (simon.horslen@seattlechildrens.org)

\begin{abstract}
Acute liver failure (ALF) was relatively easy to recognise in the days before liver transplantation became available as rescue therapy, because the diagnosis was based on end-stage disease manifestations such as profound coagulopathy, jaundice, encephalopathy and cerebral oedema (in a patient with no history of chronic liver disease). These criteria no longer help us in an era in which we struggle to define which patients are going to progress to this end-stage picture in the time necessary for evaluation and listing for life-saving transplantation. Ideally, identifying which patients will recover spontaneously or with appropriate treatment would relieve the justifiable concern that some patients receive a transplant when, given time, they would have recovered. Currently, the data to guide us in avoiding death without transplantation and unnecessary transplantation remain elusive.
\end{abstract}

S Afr Med J 2014;104(11):808-812. DOI:10.7196/SAMJ.8615

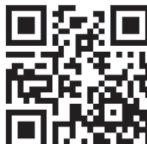

This review will focus primarily on the aspects that surround the decision to undertake liver transplantation in a child with acute liver failure (ALF). There are many excellent chapters and journal reviews that cover specific medical management of ALF and its complications; therefore this will not be addressed in this article.

\section{Definition of ALF}

Using the traditional definition of ALF, being the onset of hepatic encephalopathy within 8 weeks of the onset of liver disease, may present several challenges, not least because encephalopathy in children is difficult to assess, may be present in acute conditions other than liver failure, and is commonly a late manifestation that may not even be detected prior to the occurrence of death or transplantation. The entry criteria for the Pediatric ALF (PALF) study set the bar low (i.e. international normalised ratio (INR) $>2.0$ without encephalopathy or $>1.5$ with encephalopathy), not in an attempt to redefine ALF but in order to recruit subjects in the early stages of a disease, who may progress to full-blown liver failure. ${ }^{[1]}$

Understanding the manifestations and determining the clinical characteristics in the early stages of the disease may be crucial in developing the necessary effective prognostic tools. For the nonspecialist centre where acute hepatitis may be a common occurrence, it is difficult to determine when a patient justifies transfer to a liver transplant centre. This is particularly challenging if the distance of the tertiary centre from home is large and if resources within any given health system are limited. The entry criteria for the PALF study would seem to be a good starting point. If a patient has an INR $>2.0$ due to acute liver disease or liver disease with encephalopathy and a lesser degree of coagulopathy, referral to a transplant centre should be initiated. This does not mean that patients with an INR of 2.0 and new-onset liver disease should be listed immediately for liver transplantation, but waiting until the patient categorically needs a transplant would be to leave no time for work-up, listing and identification of a usable allograft.

Diagnostic work-up of a child with ALF The causes of ALF are protean (Table 1), but we should be aware of the range of causes within our own patient populations. Often, diagnostic work-ups are incomplete even in the context of a wellfunded multicentre study. ${ }^{[2]} \mathrm{A}$ systematic approach using standard protocols and computerised order sets may be the safest way of avoiding omissions during a diagnostic work-up, although this approach may lack focus based on specific clinical findings and lead to unnecessary tests that waste limited resources.

In general terms, diagnostic priorities include the common diseases and those conditions significantly serious that they should be ruled out early, with second- and even third-line investigations of less likely conditions thereafter. However, in ALF, the life-threatening nature of almost any potential diagnosis, along with the time constraints imposed by a progressive disease, necessitate a complete work-up at the outset (Table 2).

Many institutions have implemented blood draw limits based on the weight of the child for routine and research testing, but it is important to remember that these are guidelines and that a full workup should be undertaken even if this requires blood transfusion once the appropriate blood samples have been drawn.

\section{Indications for liver transplantation in a child with $A L F$}

Survival from ALF in children, as in adults, has been transformed by liver transplantation, but the precise indications for liver transplant remain contentious, especially in children. ${ }^{[3,4]}$ Decisions are made on the basis of readily available data, including the clinical condition, presence of encephalopathy and cerebral oedema, diagnosis, age of patient, duration of illness, level of jaundice and various measures of coagulation, and possibly ammonia, -fetoprotein, lactate and plasma phosphate levels. Strict cut-off levels that precisely predict death or survival do not exist.

Prognostic scores have been developed to assist decisionmaking and for epidemiological descriptions, but there remains a need for clinical judgement in any decision to proceed with liver transplantation in children with ALF. Such judgements depend on dynamic assessments of the patient's disease progression and not on a single set of laboratory measurements.

Although the paediatric end-stage liver disease (PELD) scoring system was designed to evaluate severity and mortality risk for chronic liver disease in children, initial PELD scores at presentation 
Table 1. Causes of acute liver failure in infants and children

\begin{tabular}{|c|c|}
\hline Viral & $\begin{array}{l}\text { Hepatitis A } \\
\text { Hepatitis B } \\
\text { Hepatitis D } \\
\text { Hepatitis E } \\
\text { Herpes simplex } \\
\text { Varicella zoster virus } \\
\text { Epstein-Barr virus } \\
\text { Cytomegalovirus } \\
\text { Paramyxovirus } \\
\text { Adenovirus } \\
\text { Enterovirus } \\
\text { Parvovirus B19 } \\
\text { Severe acute respiratory syndrome } \\
\text { Haemorrhagic fever viruses }\end{array}$ \\
\hline Bacterial & $\begin{array}{l}\text { Septicaemia } \\
\text { Leptospirosis } \\
\text { Salmonella typhi/S. paratyphi } \\
\text { Bartonella } \\
\text { Rocky Mountain spotted fever }\end{array}$ \\
\hline Metabolic & $\begin{array}{l}\text { Hereditary fructose intolerance } \\
\text { Urea cycle disorders } \\
\text { Organic acidaemias } \\
\text { Fatty acid oxidation defects } \\
\text { Mitochondrial disorders } \\
\text { Carnitine defects } \\
\text { Wilson's disease } \\
\text { Tyrosinaemia type } 1 \\
\text { Niemann-Pick disease type C } \\
\text { Acute fatty liver of pregnancy }\end{array}$ \\
\hline Immune & $\begin{array}{l}\text { Autoimmune hepatitis } \\
\text { Haemophagocytic lymphohistiocytosis } \\
\text { Neonatal haemochromatosis } \\
\text { Autoimmune haemolytic anaemia with giant- } \\
\text { cell hepatitis }\end{array}$ \\
\hline Toxic & $\begin{array}{l}\text { Drugs/toxins/herbals } \\
\text { Amanita phalloides }\end{array}$ \\
\hline Vascular & $\begin{array}{l}\text { Budd-Chiari syndrome } \\
\text { Veno-occlusive disease } \\
\text { Ischaemic hepatitis/shock liver } \\
\text { Post cardiac surgery } \\
\text { Liver trauma }\end{array}$ \\
\hline Neoplastic & $\begin{array}{l}\text { Leukaemia } \\
\text { Lymphoma } \\
\text { Hepatocellular carcinoma }\end{array}$ \\
\hline Other & $\begin{array}{l}\text { Reye's syndrome } \\
\text { Hypothermia } \\
\text { Heat stroke } \\
\text { Massive liver resection } \\
\text { Sickle cell anaemia }\end{array}$ \\
\hline
\end{tabular}

are significantly higher among non-survivors of ALF compared with survivors. ${ }^{[5]}$

\section{Outcomes of ALF in childhood}

Before liver transplantation became an option, spontaneous survival from ALF in a cohort of children seen at King's College Hospital in London was $28 \%$, but only $4 \%$ in those who progressed to grade
IV coma. ${ }^{[6]}$ The difficulty with comparing these survival figures with current outcomes is not only the changes in care, but also in the definitions used for diagnosis. In the PALF cohort, outcome varied according to diagnosis, with the greatest transplant-free survival in acetaminophen toxicity and shock (94\% and $81 \%$ at 21 days, respectively). ${ }^{[1]}$ Transplant-free survival was lowest in nonacetaminophen, drug-induced hepatitis and also in those for whom a cause could not be determined ( $41 \%$ and $43 \%$, respectively). With the exception of the acetaminophen group, transplant rates were in the range of $20-42 \%$, with the highest rates in the indeterminate group.

Liver transplantation for ALF accounted for $12.9 \%$ of all paediatric cases from 1995 to 2002 in the Studies in Pediatric Liver Transplantation (SPLIT) database. ${ }^{[3]}$ Over a 3-year period, from 2009 to 2011, there were 241 (14.4\%) liver transplants in children listed at status 1A in the USA; this number also includes those who required emergency retransplantation for hepatic artery thrombosis and primary non-function. ${ }^{[7]}$ Outcomes of liver transplantation for ALF have generally shown poorer survival than for chronic liver failure. In the early SPLIT experience from 1995 to 2002, there was a $74 \%$ 1-year patient survival rate for ALF compared with $88.2 \%$ for all other causes. ${ }^{[3]}$

Farmer et al. ${ }^{\left[{ }^{[8]}\right.}$ summarised the published literature and described 1-year post-transplant survival in children with ALF as ranging from $67 \%$ to $93 \%$. On the basis of a multivariate analysis of data from the University of California, Los Angeles, these authors also suggested that predictors of patient survival after liver transplantation in children with ALF were: better renal function (calculated creatinine clearance $>60 \mathrm{~mL} / \mathrm{min} / 1.73 \mathrm{~m}^{2}$ ); and a duration of jaundice to encephalopathy of $>7$ days.

A series of children with ALF from Korea demonstrated a posttransplant survival rate at 1 year of $87.9 \%$, with the majority of this cohort (94\%) having received living donor allografts. ${ }^{[9]}$

At Seattle Children's, 21 children have undergone orthotopic liver transplantation for ALF since January 2005. Patient and graft survival is $95.2 \%$, with time since liver transplantation ranging from 45 days to almost 9 years (median 46 months). In two cases, a live donor was utilised, and in the deceased donor cases, blood groups were crossed in nine; two with compatible blood groups and seven with $\mathrm{ABO}$ incompatible grafts. A single death occurred at 8 days post-transplant in a 6-week-old infant with neonatal haemochromatosis.

\section{Obstacles to optimal management of a paediatric patient with ALF}

The ideal scenario would be to identify an aetiology and to start treatment expeditiously in those with diagnosable conditions. Diagnoses that are potentially treatable include autoimmune hepatitis, drug toxicity and certain infectious conditions. For those with a diagnosis for which an effective treatment is not available, or for those cases where the precise diagnosis continues to evade elucidation, a reliable prognostic indicator would determine whether the patient will progress to terminal stage or will improve with supportive therapy.

To bridge patients either to recovery or to transplantation, effective support of liver function would prolong the time in which careful transplant work-up and identification of a suitable organ, either from a live or deceased donor, can take place. For those patients with irrecoverable liver failure and in whom the expectation of the native liver's regenerative potential is negligible, orthotopic liver transplantation with total hepatectomy should be undertaken expeditiously. As with the majority of current transplant patients, these patients would need lifetime monitoring and long-term immunosuppression, but outcomes, both short- and long-term, are now excellent in experienced centres. 
Table 2. Diagnostic work-up for infants and children with acute liver failure

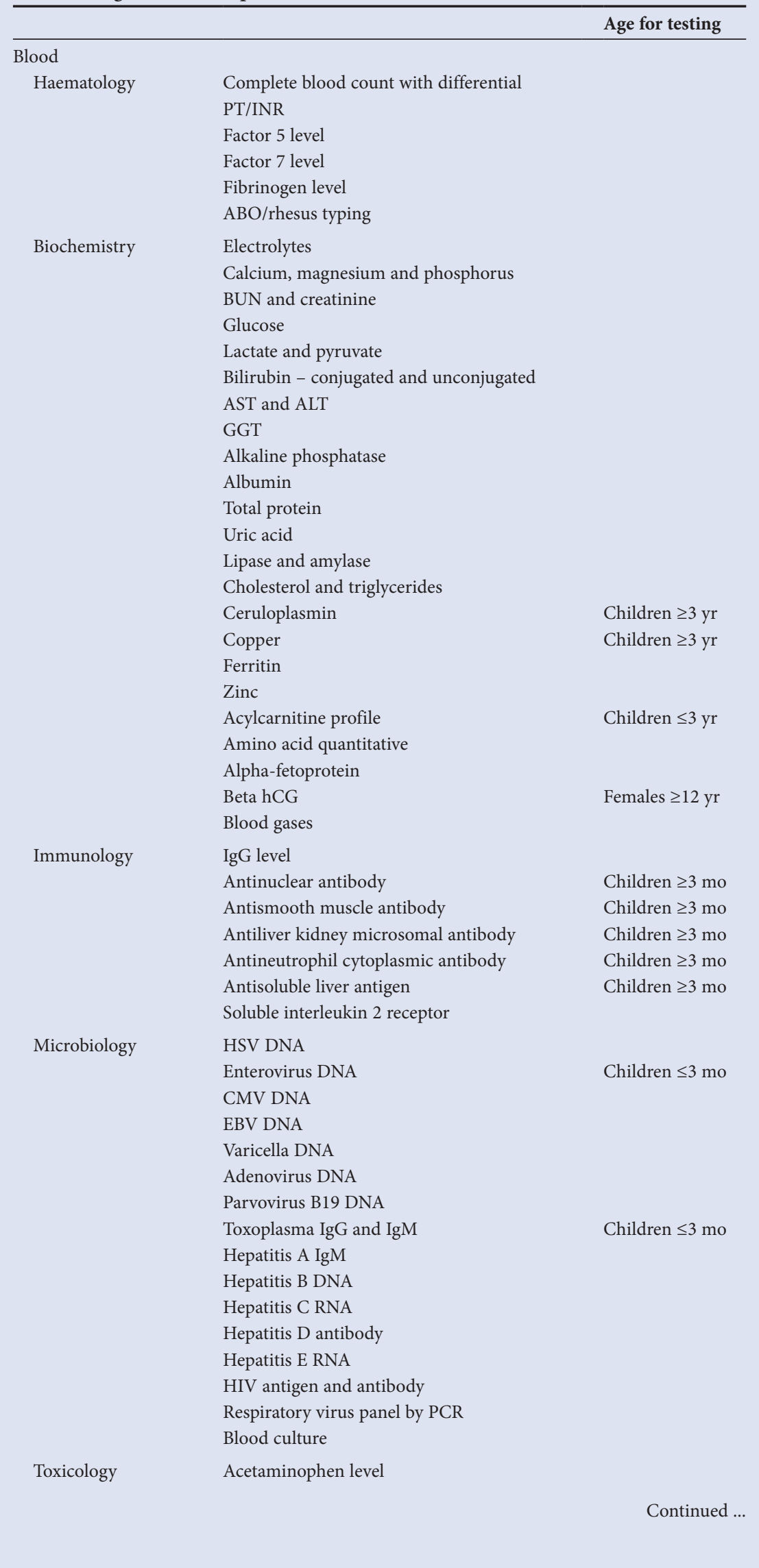

There is also a group of patients in whom the liver has failed acutely, and survival can only be expected with the rapid return to normal hepatic function but in whom longterm hepatic regenerative potential exists. This is most clear in those patients with severe acetaminophen overdose, but also includes patients with unknown and other specific causes, such as Amanita mushroom poisoning. Greater use of auxiliary transplantation might be envisaged in these situations. Thus, when supported through the acute illness, the native liver has the opportunity to regenerate and the auxiliary allograft can be allowed to gradually involute. Finally, there are some conditions where transplantation would be futile, such as a generalised mitochondrial cytopathy, in which cases optimal palliative care may be implemented.

Barriers to applying this approach abound. Worldwide, providers are confronted with: a lack of reliable prognostic tools; a lack of proven liver support techniques; inefficient transplant work-up and organ availability; and the application of auxiliary liver transplantation in only a very limited number of transplant centres.

\section{Prognostic tools}

Numerous attempts have been made over the years to amalgamate clinical and laboratory data into models that will predict death without transplantation for patients with acute hepatic insufficiency. Examples include the King's College Hospital criteria (KCHC), the Clichy score and the liver injury unit (LIU) score, but all have fallen well short of ideal. ${ }^{[4,10]}$ Clinically, the majority of physicians are quite accurate at predicting death within an hour or two of the event, but 5 or 7 days (or maybe even longer) preceding the event is a completely different proposition. This time interval is required to safely list a patient for transplant and to find a suitable organ before the patient is in too perilous a state to achieve optimal outcomes from the subsequent transplant, or to be bold enough not to list a patient who may recover spontaneously. One of the difficulties may be that the dice are not necessarily cast at these temporally distant points. In adults with ALF, Bernal et al..$^{[1]}$ described an improvement in overall survival in ALF from $17 \%$ in the 1970 s to $62 \%$ in the period 2004 - 2008, and even in those not undergoing transplantation, survival rose from $17 \%$ to $48 \%$. With medical advances and the potential predictive power of any of the prognostic models in mind, care is modified, and thus the power to predict outcome diminishes. This is a recognised phenomenon in economics and politics whereby the more 
Table 2. (continued) Diagnostic work-up for infants and children with acute liver failure

\begin{tabular}{lll}
\hline & & Age for testing \\
\hline Urine & Urinalysis & \\
& Urine culture & \\
& Urinary organic acids (including \\
& succinylacetone) & Children $\leq 3 \mathrm{yr}$ \\
& Urinary copper quantitation & Children $\geq 3 \mathrm{yr}$ \\
& Urinary toxicology screen & \\
& Abdominal ultrasound & \\
& ECG & \\
Other studies & Echocardiogram & \\
&
\end{tabular}

authoritative the prediction, the less likely it is to be realised because the prediction itself modifies behaviour. ${ }^{[12]}$ In essence, any predictive model of outcome will be undermined by its own success. This may explain why the greatest predictive power that each of the current models attain is with the first cohort to which it is applied.

Another concern about the available predictive models is that they tend to lack the ability to account for the dynamic nature of disease progression. The serial application of a model during the course of illness has been attempted using PELD scores, but this accounts for a very limited portion of the overall data used in managing a patient. ${ }^{[13]}$ There are also concerns specific to particular prognostic tools. For example, the Clichy criteria demand the presence of encephalopathy, which may only be an immediate premortem occurrence in young children, if it appears at all. ${ }^{[14]}$ The $\mathrm{KCHC}$ failed to stand up to scrutiny when applied to the PALF cohort, although Ciocca et al. ${ }^{[15]}$ suggested that the KCHC performed well in a group of 210 children from South America above 1 year of age. ${ }^{[16]}$ In Denver, a LIU score was devised based on total bilirubin, prothrombin time/international normalised ratio (PT/INR) and blood ammonia; it was a good predictor of death or liver transplantation for children with ALF, but on close examination it was far less effective at predicting death than it was at predicting survival after transplantation - seemingly a self-fulfilling prophecy. ${ }^{[17]}$ Recently, advanced computing techniques have been applied in the form of artificial neural networks, and as the predictions made by such a system are continuously refined by further data inputs, it may be hoped that the evolving changes in care will be reflected in updated predictive models. ${ }^{[18]}$ Another approach is being actively investigated in the PALF collaborative using Bayesian mathematical methods to model dynamic networks of plasma cytokines in order to identify patterns predictive of spontaneous survival or eventual death in those not transplanted. ${ }^{[19]}$

Extracorporeal liver support, analogous to renal dialysis, has a substantial history of oneoff experiments, preclinical trials, uncontrolled clinical applications and an occasional controlled study, but proof of effectiveness has yet to be clearly demonstrated. Experience of cross-circulation and extracorporeal liver perfusion from the pretransplant era demonstrated the effectiveness in terms of waking patients with ALF from advanced coma and stabilising haemodynamic parameters, but as soon as the treatment was discontinued, the patients deteriorated again and ultimately no survival advantage could be demonstrated. With the advent of liver transplantation, such approaches have been considered, not to prevent the need for transplantation, but as potential bridges to transplantation. Techniques that have been tried fall into two basic groups: toxin removal, and more holistic attempts to restore global liver function (detoxification, excretion, hepatic synthetic function, etc.). ${ }^{[20]}$

Toxin removal techniques range from exchange transfusion, plasmapheresis and haemofiltration through charcoal columns, to modularised recirculating albumin dialysis or plasma exchange. None of these techniques, though quite widely applied clinically, have been demonstrated to benefit survival.

Biological or bioartificial systems of liver support include human and xenogeneic extracorporeal liver perfusion and a number of bioreactors seeded with hepatocytes of human or porcine origin, or immortalised hepatocyte-like cell lines. Anecdotal descrip-

\section{Extracorporeal support of liver function}

tions suggest improved function, but the methodological challenges in designing and powering studies, not to mention the difficulty funding them, has meant that any promise is as yet unfulfilled. The closest anyone has come to proving clinical efficacy was the study by Demetriou et al. ${ }^{[21]}$ However, the 'bioartificial liver' used in this study has not appeared as a commercial product since this study was reported 10 years ago.

\section{Transplant work-up and organ availability}

Owing to the vagaries of deceased donor allograft availability, once the decision to consider transplant for a patient in acute failure is made, the work-up and selection should be completed as rapidly as possible. This can be achieved in select centres in a matter of hours, but in order to do so without mistakes or corner-cutting, and to maintain compliance with the everincreasing regulations, considerable planning along with the need to establish protocols is required for such emergency situations.

Many countries prioritise allocation of livers to children and to patients with fulminant failure. In the USA, national sharing of deceased donor livers is available to patients listed as status 1A. For children, the use of technical variant grafts is important to facilitate emergent transplantation, and the willingness and ability to cross blood groups for $\mathrm{ABO}$-incompatible liver transplantation broadens the potential donor pool.

The median time from being listed for a liver transplant to being offered a usable organ is between 2 and 3 days in the US, but there are times when the wait has been considerably longer. Living donor transplantation may be seen as a potential solution for this dilemma; however, it also raises concerns of its own. Can a thorough living donor work-up be carried out safely in an emergency? How do teams avoid the possibility of donor consent due to feelings of guilt, duty or overt coercion? However, as the experience in Asian countries shows, and to a lesser extent our own experience, living donor transplantation in emergency situations can be both feasible and successful..$^{[9]}$

\section{Auxiliary transplantation for ALF}

The concept of leaving a portion of the native liver in situ when liver transplantation is undertaken, with the expectation of native liver regeneration, is extremely attractive. The history of this procedure stretches back to animal experiments in the 1950s and human experience starting in 1964, although success was elusive until the 1980s. ${ }^{[22]}$ The 
majority of recipients of an auxiliary liver graft can be expected to have regeneration of their native liver, and it has been estimated that two-thirds of long-term survivors will eventually be free of immunosuppression. Once native liver regeneration has been assured by biopsy, computed tomography volumetry and hepatic scintigraphy, a patient can gradually be weaned off immunosuppression and the graft will involute. Occasionally, acute rejection, hepatic artery thrombosis and graft infarction may occur with over-aggressive withdrawal of immunosuppression, necessitating surgical removal of the allograft.

Despite well-described series from centres around the world achieving survival rates equivalent to those of other forms of liver transplant, there has not been widespread uptake of the technique. Reasons for the lack of enthusiasm for this approach have not been formally stated, but probably relate to the additional complexity of the technique and its limited applicability. Right or left hemihepatectomy is required to create space for the allograft, which is challenging in a patient with coagulopathy and the need to maintain good cerebral perfusion pressures throughout the operation.

It is generally accepted that auxiliary transplantation is not a good option in the face of raised intracranial pressure or haemodynamic instability, and technical considerations tend to preclude it in the very young. In the King's College Hospital series of 128 liver transplants in children with ALF, 20 received auxiliary allografts and 14 of 17 survivors had native liver regeneration. ${ }^{[2]}$ Kato et al. also reported six cases in children with $100 \%$ survival, but only one patient had been weaned from immunosuppression at the time of reporting. ${ }^{[23]}$

\section{Conclusion}

ALF in children is as challenging as any field of clinical medicine. The advent of liver transplant and the continuous improvements in outcomes have meant survival for many children in the modern era who would previously have died. However, the decision to transplant or to wait remains fraught with uncertainty. We still lack the tools to accurately predict which patients will survive without transplantation. Truly functional liver support is not available to prolong the period of observation during which more precise diagnosis may be possible, allowing a clearer sense of the individual disease progression to become apparent and more time to find a good allograft if the need for liver transplantation becomes inevitable. Auxiliary liver transplantation, although conceptually very attractive, is available in few centres and is only feasible in a small proportion of potential recipients. Careful clinical judgement remains our best defence against children dying from ALF for want of a transplant, and the occasional unnecessary transplant in a child with ALF who might have recovered without transplantation.

\section{References}

1. Squires RH Jr, Shneider BL, Bucuvalas J, et al. Acute liver failure in children: The first 348 patients in the pediatric acute liver failure study group. J Pediatr 2006;148(5):652-658. [http://dx.doi. org/10.1016/j.jpeds.2005.12.051

2. Narkewicz MR, Dell Olio D, Karpen SJ, et al. Pattern of diagnostic evaluation for the causes of pediatric acute liver failure: An opportunity for quality improvement. J Pediatr 2009;155(6):801-806. [http:// dx.doi.org/10.1016/j.jpeds.2009.06.005

3. Baliga P, Alvarez S, Lindblad A, Zeng L. Posttransplant survival in pediatric fulminant hepatic failure: The SPLIT experience. Liver Transpl 2004;10(11):1364-1371. [http://dx.doi.org/10.1002/lt.20252]

4. O'Grady J. Timing and benefit of liver transplantation in acute liver failure. J Hepatol 2014;60(3):663670. [http://dx.doi.org/10.1016/j.jhep.2013.10.024]

5. Sanchez MC, D'Agostino DE. Pediatric end-stage liver disease score in acute liver failure to assess poor prognosis. I Pediatr Gastroenterol Nutr 2012;54(2):193-196. [http://dx.doi.org/10.1097/ MPG.0b013e3182349a04]

6. Psacharopoulos HT, Mowat AP, Davies M, Portmann B, Silk DB, Williams R. Fulminant hepatic failure in childhood: An analysis of 31 cases. Arch Dis Child 1980;55(4):252-258.

7. Kim WR, Stock PG, Smith JM, et al. OPTN/SRTR 2011 Annual Data Report: Liver. Am J Transplant 2013;13(Suppl 1):73-102. [http://dx.doi.org/10.1111/ajt.12021]

8. Farmer DG, Venick RS, McDiarmid SV, et al. Fulminant hepatic failure in children: Superior and durable outcomes with liver transplantation over 25 years at a single center. Ann Surg 2009;250(3):484493. [http://dx.doi.org/10.1097/SLA.0b013e3181b480ad]

9. Oh SH, Kim KM, Kim DY, et al. Improved outcomes in liver transplantation in children with acute liver failure. J Pediatr Gastroenterol Nutr 2014;58(1):68-73. [http://dx.doi.org/10.1097/ MPG.0b013e3182a80362]

10. Liu E, MacKenzie T, Dobyns EL, et al. Characterization of acute liver failure and development of a continuous risk of death staging system in children. J Hepatol 2006;44(1):134-141. [http://dx.doi. org/10.1016/j.jhep.2005.06.021]

11. Bernal W, Hyyrylainen A, Gera A, et al. Lessons from look-back in acute liver failure? A single centre experience of 3300 patients. J Hepatol 2013;59(1):74-80. [http://dx.doi.org/10.1016/j. jhep.2013.02.010]

12. Taleb NN. The Black Swan: The Impact of the Highly Improbable. New York: Random House, 2010.

13. Rajanayagam J, Coman D, Cartwright D, Lewindon PJ. Pediatric acute liver failure: Etiology, outcomes, and the role of serial pediatric end-stage liver disease scores. Pediatr Transplant 2013;17(4):362-368. [http://dx.doi.org/10.1111/petr.12083]

14. Squires RH, Jr. Acute liver failure in children. Semin Liver Dis 2008;28(2):153-166. [http://dx.doi. org/10.1055/s-2008-1073115]

15. Ciocca M, Ramonet M, Cuarterolo M, Lopez S, Cernadas C, Alvarez F. Prognostic factors in paediatric acute liver failure. Arch Dis Child 2008;93(1):48-51. [http://dx.doi.org/10.1136/adc.2006.115113]

6. Sundaram V, Shneider BL, Dhawan A, et al. King's College Hospital Criteria for non-acetaminophen induced acute liver failure in an international cohort of children. J Pediatr 2013;162(2):319-323. [http://dx.doi.org/10.1016/j.jpeds.2012.07.002]

17. Lu BR, Zhang S, Narkewicz MR, Belle SH, Squires RH, Sokol RJ. Evaluation of the liver injury unit scoring system to predict survival in a multinational study of pediatric acute liver failure. J Pediatr 2013;162(5):1010-1016. [http://dx.doi.org/10.1016/j.jpeds.2012.11.021]

18. Rajanayagam J, Frank E, Shepherd RW, Lewindon PJ. Artificial neural network is highly predictive of outcome in paediatric acute liver failure. Pediatr Transplant 2013;17(6):535-542. [http://dx.doi org/10.1111/petr.12100]

19. Azhar N, Ziraldo C, Barclay D, Rudnick DA, Squires RH, Vodovotz Y. Analysis of serum inflammatory mediators identifies unique dynamic networks associated with death and spontaneous survival in pediatric acute liver failure. PLoS ONE 2013;8(11):e78202. [http://dx.doi.org/10.1371/journal. in pediatric

20. McKenzie TJ, Lillegard JB, Nyberg SL. Artificial and bioartificial liver support. Semin Liver Dis 2008;28(2):210-217. [http://dx.doi.org/10.1055/s-2008-1073120]

21. Demetriou AA, Brown RS Jr, Busuttil RW, et al. Prospective, randomized, multicenter, controlled trial 1. Demetriou AA, Brown RS Jr, Busuttil RW, et al. Prospective, randomized, multicen
of a bioartificial liver in treating acute liver failure. Ann Surg 2004;239(5):660-667.

22. Ciria R, Davila D, Heaton N. Auxiliary liver transplantation in children. Curr Opin Organ Transplant 2011;16(5):489-493. [http://dx.doi.org/10.1097/MOT.0b013e32834a94cf]

23. Kato T, Selvaggi G, Levi D, et al. Routine use of auxiliary partial orthotopic liver transplantation for 3. Kato T, Selvaggi G, Levi D, et al. Routine use of auxiliary partial orthotopic liver transplantation for
children with fulminant hepatic failure: Preliminary report. Transplant Proc 2006;38(10):3607-3608. [http://dx.doi.org/10.1016/j.transproceed.2006.10.038] 